\section{MYOD1 involvement in myopathy}

F. Lopes ${ }^{\mathrm{a}, \mathrm{b}, \mathrm{c}}$, M. Miguet ${ }^{\mathrm{c}, \mathrm{d}}$,

B. E. Mucha ${ }^{\mathrm{c}}$, J. Gauthier ${ }^{\mathrm{c}, \mathrm{e}}$, V. Saillour ${ }^{\mathrm{c}, \mathrm{f}}$,

C.-T. É. Nguyen ${ }^{\mathrm{c}, \mathrm{g}}$, M. Vanasse , $, \mathrm{g}, *$, $^{\mathrm{s}}$

B. Ellezam ${ }^{\mathrm{c}, \mathrm{h}}$, J. L. Michaud ${ }^{\mathrm{c}, \mathrm{g}}$,

J.-F. Soucy, and P. M. Campeau ${ }^{\mathrm{c}, \mathrm{g}}$

${ }^{\mathrm{a}}$ Life and Health Sciences Research Institute (ICVS), School of Medicine, University of Minho, Braga, 'ICVS/3B's PT Government Associate Laboratory, Braga/Guimarães, Portugal, ${ }^{\mathrm{c}} \mathrm{CHU}$ Sainte-Justine Research Center, Université de Montréal, Montreal, Quebec, Canada, ${ }^{\mathrm{d}} \mathrm{CHU}$ de Strasbourg, Pôle de biologie, Alsace, France, ${ }^{\mathrm{e}}$ Medical Biological Unit, Molecular Diagnostic Laboratory, Sainte-Justine University Hospital Center, Montreal, QC, ${ }^{\mathrm{f}}$ Centre de génomique clinique pédiatrique intégré, Génome Québec et CHU Sainte-Justine, Montreal, QC,

${ }^{\mathrm{g}}$ Department of Pediatrics, Sainte-Justine University Hospital Center, Montreal, $Q C$, and ${ }^{\mathrm{h}}$ Department of Pathology, CHU Sainte-Justine, Montreal, QC, Canada

Correspondence: P. M. Campeau, CHU Sainte-Justine, 3175, Côte-Ste-Catherine, Montreal, H3T 1C5 QC, Canada (tel.: + 1514345 4931, ext 7146; fax: + 1514345 4766;

e-mail: p.campeau@umontreal.ca).

Keywords: Myogenic Differentiation 1, myopathy, respiratory insufficiency

doi:10.1111/ene.13782

Received: 19 February 2018

Accepted: 17 August 2018

\section{Introduction}

Myogenic Differentiation 1 (MYOD1) encodes a transcription factor that plays an important role in myogenic determination into mature skeletal muscle [1]. The first loss-of-function mutation of $M Y O D 1$ in humans was described in three siblings with perinatal lethal fetal akinesia [2]. Here, we describe an individual with a loss-of-function mutation in the $M Y O D 1$ gene and a congenital myopathy with mild motor developmental delay, ptosis and breathing and feeding difficulties.

\section{Case report}

The patient, an 8-year-old girl, presented a history of respiratory infections, hypotonia, ptosis, motor delay and failure to thrive, resulting in the placement of a gastrostomy by the age of 2 years. Bilevel positive airway pressure during naps and night-time sleep was started for severe nocturnal hypercapnia. Muscular function improved with age and remained stable with mildly decreased endurance and balance. Pulmonary imaging showed bilateral high diaphragmatic domes without pulmonary hypoplasia (Appendix S1) and diaphragmatic hypomobility on fluoroscopy. Abdominal ultrasonography at 2 years revealed bilateral small kidney $(-2 \mathrm{SD})$ without other anomalies. The patient had a homozygous nonsense variant (c.697G > T; p.Glu233*) that segregated with the phenotype (parents and unaffected siblings are heterozygous carriers). Informed consent was obtained.

\section{Discussion}

In the present case, we can observe that the most severely affected musculature is the diaphragm. The lung hypoplasia observed in the patient could be due to the absence of mechanical forces originated by the proper functioning of the diaphragm. Similar conclusions were drawn from studies in a mouse model of Myod1 and Dmd deficiency [3,4].

In 2016, the first MYOD1 mutation in humans was reported by Watson et al. [2] in three siblings with perinatal lethal fetal akinesia. Although the severity of the phenotype is different there are still many similarities with the present individual (clinical comparison in Table 1). All patients present with triangular facies, generalized muscle weakness, renal anomalies and alterations in diaphragmatic function with respiratory insufficiency of variable degree. The previously described pathogenic variant introduces a stop codon in exon 1 within the basic motif of the bHLH protein domain and probably leads to nonsense-mediated decay with absence of MYOD1 protein.
In contrast, the new stop codon in the index patient is localized within 13 bp of the exon 2 /exon 3 junction

(Appendix S1), and is thus predicted not to lead to nonsense-mediated decay [5].

Through this work, we thus contribute to a better understanding of the MYOD1 myopathy phenotypic spectrum.

\section{Acknowledgements}

We thank the individual and family. Funding was provided by The Fonds de recherche du Québec - Santé (FRQS) and Canadian Institutes of Health Research (CIHR) to P.M.C., Fundação para a Ciência e Tecnologia (FCT) with the fellowship SFRH/BD/84650/2010 to F.L. and Groupe Pasteur Mutualité Foundation (GPM Foundation) to M.M.

\section{Disclosure of conflicts of interest}

The authors declare no financial or other conflicts of interest.

\section{Supporting Information}

Additional supporting information may be found online in the Supporting Information section at the end of the article.

Appendix S1. Myogenic Differentiation 1 involvement in myopathy.

\section{References}

1. Sabourin LA, Girgis-Gabardo A, Seale P, Asakura A, Rudnicki MA. Reduced differentiation potential of primary MyoD-/myogenic cells derived from adult skeletal muscle. J Cell Biol 1999; 144: 631-643.

2. Watson CM, Crinnion LA, Murphy H, et al. Deficiency of the myogenic factor MyoD causes a perinatally lethal fetal akinesia. J Med Genet 2016; 53: 264-269.

3. Inanlou MR, Dhillon GS, Belliveau AC, et al. A significant reduction of the diaphragm in mdx:MyoD-/-(9th) embryos suggests a role for MyoD in the diaphragm development. Dev Biol 2003; 261: 324-336.

4. Inanlou M-R, Kablar B. Abnormal development of the diaphragm in $\mathrm{mdx}$ : MyoD-/-(9th) embryos leads to pulmonary hypoplasia. Int J Dev Biol 2003; 47: 363-371.

5. Nagy E, Maquat LE. A rule for terminationcodon position within intron-containing genes: when nonsense affects RNA abundance. Trends Biochem Sci 1998; 23: 198199.

*Posthumously. 
Table 1 Clinical comparison of the four individuals with Myogenic Differentiation 1 homozygous mutations

\begin{tabular}{|c|c|c|c|c|}
\hline & \multirow[b]{2}{*}{ Present individual } & \multicolumn{3}{|l|}{ Watson et al. (2016) } \\
\hline & & III.1 & III.2 & III.4 \\
\hline Gender & Female & Male & Male & Female \\
\hline \multicolumn{5}{|l|}{ Family history } \\
\hline Consanguinity & + & + & + & + \\
\hline \multicolumn{5}{|l|}{ Pre-natal and perinatal history } \\
\hline Pre-natal anomalies & - & $\begin{array}{l}\text { Cystic hygroma } \\
\text { polyhydramnios }\end{array}$ & Polyhydramnios & Cystic hygroma \\
\hline Birth & At term & $35+5$ & $35+1$ & 37 \\
\hline Growth & Normal birth weight & Low birth weight & Low birth weight & Low birth weight \\
\hline Apgar & $\mathrm{ND}$ & $1-1$ & $1-1$ & $1-1$ \\
\hline Neonatal death & - & + & + & + \\
\hline \multicolumn{5}{|l|}{ Cranio facial symptoms } \\
\hline Triangular face & + & + & + & + \\
\hline Downslanted palpebral fissures & + & + & ND & ND \\
\hline Ptosis & + & ND & ND & ND \\
\hline Proptosis & + & ND & ND & ND \\
\hline Mandible & Prognathia & Small chin & Small chin & Small chin \\
\hline Palate & High-arched & Cleft & Cleft & Cleft \\
\hline Dental malocclusion & + & NA & NA & NA \\
\hline \multicolumn{5}{|l|}{ Respiratory symptoms } \\
\hline $\begin{array}{l}\text { Respiratory insufficiency due to muscle } \\
\text { weakness }\end{array}$ & + & + & + & 20 \\
\hline Diaphragm & High domes & Right-sided eventration & Very high domes & Extremely high domes \\
\hline Pulmonary hypoplasia & - & + & + & + \\
\hline Ventilatory support & Nocturnal BiPAP & Ventilator dependent & & \\
\hline \multicolumn{5}{|l|}{ Musculoskeletal symptoms } \\
\hline Generalized muscle weakness & + & + & + & + \\
\hline $\begin{array}{l}\text { Fatigable weakness of swallowing } \\
\text { muscles }\end{array}$ & + & ND & ND & ND \\
\hline Clinodactyly/digit overlapping & + & + & + & - \\
\hline \multicolumn{5}{|l|}{ Cutaneous symptoms } \\
\hline Congenital, generalized hypertrichosis & + & ND & ND & ND \\
\hline \multicolumn{5}{|l|}{ Genitourinary symptoms } \\
\hline Cryptorchidism & NA & Bilateral & Unilateral & NA \\
\hline Renal anomaly & $\begin{array}{l}\text { Small kidneys } \\
(-2 \mathrm{SD})\end{array}$ & $\begin{array}{l}\text { Bilateral renal pelvis } \\
\text { distension }\end{array}$ & Unilateral hydronephrosis & Renal hypoplasia \\
\hline
\end{tabular}

BiPAP, bilevel positive airway pressure; NA, not applicable; ND, not done; +, present; -, absent. 